\title{
ESTABELECIMENTO INICIAL DE PLÂNTULAS DE Myracrodruon urundeuva ALLEMÃO EM DIFERENTES SUBSTRATO ${ }^{1}$
}

\author{
Alexandro Pereira Andrade², Camilla de Carvalho de Brito ${ }^{3}$, Jorge da Silva Júnior ${ }^{4}$, Fábio Del Monte \\ Cocozza $^{4}$ e Marcos Antônio Vanderlei Silva ${ }^{4}$
}

\begin{abstract}
RESUMO - Objetivou-se com este trabalho avaliar o crescimento inicial de plântulas de $M$. urundeuva estabelecidas em diferentes substratos. O trabalho foi realizado no Laboratório de Sementes e no Viveiro de Mudas da Universidade Estadual da Bahia (UNEB), Barreiras, BA. As sementes foram coletadas de árvores daquela universidade. Foi utilizado o delineamento inteiramente casualizado com seis tratamentos e quatro repetições, sendo os tratamentos T1: solo; T2: areia; T3: solo + areia + esterco; T4: casca de madeira; T5: bagaço de cana-de-açúcar + esterco; e T6: bagaço de cana-de-açúcar + esterco + cinzas. A semeadura foi realizada em bandejas plásticas, com diferentes substratos, utilizando-se 20 sementes, colocadas a uma profundidade de 1,0 cm. Foram avaliados o índice de velocidade de emergência (\%), a altura da parte aérea e da radícula, o comprimento das plântulas e das folhas, o número de folhas e as massas verde e seca da parte aérea e da radícula. Plântulas estabelecidas utilizando casca de madeira como substratos obtiveram melhores resultados quanto ao número e comprimento das folhas, altura da parte aérea e massa verde e seca da parte aérea. Em contraste, os percentuais de índice de velocidade de emergência obtiveram os piores resultados em plântulas estabelecidas em substratos com casca de madeira. Os resultados de radículas não diferiram entre as plântulas estabelecidas com os diferentes substratos. Os substratos contendo composto de casca de madeira ou bagaço de cana + esterco forneceram as melhores condições para o crescimento inicial de plântulas de M. urundeuva.
\end{abstract}

Palavras-chave: Aroeira; Germinação; Sementes florestais.

\section{INITIAL ESTABLISHMENT OF Myracrodruon urundeuva SEEDLINGS IN DIFFERENT SUBSTRATES}

\begin{abstract}
The objective of this study was to evaluate the initial growth of seedlings of M. urundeuva established in different substrates. The study was carried out at the Laboratory of Seeds and Nursery Plants of UNEB, Barreiras, Bahia State, Brazil. Seeds were collected from trees at the University Campus. The experimental design was a completely randomized with four replications and six treatments: T1 soil, T2 sand, T3 soil + sand + manure, T4 wood bark, T5 sugar cane bagasse + manure; T6 sugar cane bagasse + manure + ash. The seeds were sown in plastic trays with different substrates, using 20 seeds at $1.0 \mathrm{~cm}$ of depth. We evaluated the index of emergency speed (\%), height of shoot and radicle, length of seedlings and leaves, leaf number, fresh and dry mass of shoots and radicle. Established seedlings using wood bark as substrates obtained better results regarding to the number and length of leaves, shoot height, fresh and dry mass of shoots. In contrast, percentage of emergency speed index obtained the worst results in seedlings established on substrates with wood bark. The rootlets results did not differ between the seedlings established in different substrates. The substrates containing wood bark or sugar cane bagasse + manure, provide the best conditions for the initial growth of M. urundeuva seedlings. Keywords: Mastic; Germination; Forest seeds.
\end{abstract}

\footnotetext{
${ }^{1}$ Recebido em 30.11.2011 aceito para publicação em 06.08.2013.

${ }^{2}$ Programa de Pós-Graduação em Zootecnia na Universidade Estadual do Sudoeste da Bahia, UESB, Brasil. E-mail: <alexandro_andrade@hotmail.com>.

${ }^{3}$ Programa de Pós-Graduação em Ciências Ambientais, ICADS, UFBA, Barreiras, Bahia, Brasil. E-mail: <camilla_carvalho_3@hotmail.com>.

${ }^{4}$ Faculdade de Agronomia, UNEB, Campus IX, Barreiras, Bahia, Brasil. E-mail: <jsjbaiano@hotmail.com>, <fabiococozza@yahoo.com.br>e<maavsilva@uneb.br>.
} 


\section{INTRODUÇÃO}

O Cerrado é um dos ecossistemas do Brasil que ocorre hoje em áreas relativamente restritas, devido à utilização pelo homem. Recentemente, esforços vêm sendo realizados para a manutenção e conservação dessas áreas, tendo em vista a importância da biodiversidade vegetal e da fauna nelas presentes (SILVA et al., 2006). A conservação e uso sustentável de áreas do Cerrado dependem, ainda, de conhecimentos básicos sobre o desenvolvimento e adaptação das espécies ocorrentes nesse ecossistema (OLIVEIRA et al., 2005).

A Myracrodruon urundeuva Allemão é uma espécie arbórea pertencente à família Anacardiaceae, conhecida popularmente como aroeira, que ocorre naturalmente no Brasil, na Bolívia, no Paraguai e na Argentina (SANTIN; LEITÃO FILHO, 1991). No Brasil, aparece desde o Ceará até o Paraná e Mato Grosso do Sul, sendo mais frequente na Região Nordeste (LORENZI, 1992). A planta é decídua, heliófila e seletiva xerófila, característica de terrenos secos e rochosos, e está presente em agrupamentos densos, tanto em formações abertas e secas quanto em formações fechadas e úmidas (LORENZI, 1992; CARVALHO, 1994).

Comparada com outras espécies com características nobres e alto valor econômico, a $M$. urundeuva tem sua exploração predatória extensiva, acarretando o comprometimento de suas populações naturais, e, portanto, requer estudos para garantir sua conservação. Em decorrência dessa ampla utilidade e exploração, a espécie foi incluída como espécie ameaçada de extinção na categoria vulnerável (IBAMA, 1992).

A produção de mudas para constituição de áreas onde essa espécie não aparece torna-se de fundamental importância. No entanto, o custo com substratos comerciais pode vir a onerar os custos de produção, sendo necessário o estudo da utilização de substratos alternativos na produção de mudas de aroeira.

O substrato deve apresentar características físicas e químicas que proporcionem bom crescimento do sistema radicular (ANDRIOLO, 1999) e também proporção correta entre as fases sólida e líquida, o que favorece a atividade fisiológica das raízes e, ao mesmo tempo, evita as condições favoráveis ao aparecimento de moléstias radiculares, especialmente as podridões fúngicas e bacterianas.

Revista Árvore, Viçosa-MG, v.37, n.4, p.737-745, 2013
Segundo Guerra et al. (2006), saber a respeito da morfologia de sementes e plântulas nos estágios iniciais de desenvolvimento contribui para o conhecimento do processo reprodutivo das espécies vegetais, servindo de subsídio para a produção de mudas. Além disso, é fundamental para a melhor compreensão do processo de estabelecimento da planta em condições naturais da floresta.

Para Melo et al. (2004), estudos sobre morfologia de sementes e plântulas auxiliam na identificação botânica da espécie, na interpretação dos testes de laboratório e no reconhecimento da espécie em bancos de sementes do solo e em fase de plântulas em formações florestais.

De acordo com Morgado et al. (2000), é importante a condução de pesquisas visando à qualidade de substrato para produção de mudas mais vigorosas, mais resistentes às adversidades climáticas e a custos mais baixos. Oliveira et al. (2008) relataram que, em razão da tendência de ocupação de terras com futuros plantios florestais de forma equilibrada, é necessário produzir, avaliar e selecionar substratos de fácil aquisição e que atendam às exigências das espécies.

Segundo Zietemann e Roberto (2007), o substrato destina-se a sustentar as plantas durante o enraizamento e servir-lhes de fonte de nutrientes. No Brasil, diferentes matérias-primas de origem mineral e orgânica são usadas puras ou em misturas para compor substratos para plantas. Como exemplo, citam-se a casca de arroz (in natura, carbonizada ou queimada), vermiculita, espuma fenólica, areia, subprodutos da madeira como serragem e maravalha, fibra de madeira, compostos de lixo domiciliar urbano e de restos de poda e vermicomposto (SODRE, 2007).

Portanto, objetivou-se neste trabalho o estudo dos aspectos morfológicos das sementes e do crescimento inicial de plântulas de aroeira estabelecidas em diferentes substratos.

\section{MATERIAL E MÉTODOS}

Este trabalho foi realizado no Laboratório de Sementes e no Viveiro de Mudas da Universidade do Estado da Bahia Campus IX, localizada no Município de Barreiras, BA. As sementes foram coletadas em árvores do entorno da Universidade, no mês de setembro de 2009, e armazenadas em saco plástico no laboratório depois de serem selecionadas, com o descarte das que apresentavam má conformação e injúrias. 
Nas análises morfológicas foram utilizadas 100 sementes, escolhidas aleatoriamente, em que foram avaliadas suas dimensões de comprimento e largura com a utilização de um paquímetro, bem como o peso de 100 sementes, obtido através de balança analítica de precisão.

O delineamento inteiramente casualizado (DIC) constou de seis tratamentos (tipos de substratos) e quatro repetições. Os tratamentos utilizados foram: solo puro (T1); areia lavada e esterilizada (T2); solo + areia + esterco bovino (2:1:1) (T3); composto de casca de madeira moída (T4); bagaço de cana + esterco bovino $(1: 1)$ (T5) e bagaço de cana + esterco + cinza $(1: 1: 1)$ (T6).

O bagaço de cana é o resíduo fibroso resultante da extração de caldo dos colmos de cana-de-açúcar, o qual foi triturado em máquina forrageira estacionária antes de ser utilizado no tratamento. As cinzas e cascas de madeira moída foram oriundas de caldeira à lenha de uma esmagadora de soja do próprio município.

Em cada substrato utilizado foram coletadas amostras, embaladas em sacos plásticos identificados e levados ao Laboratório de Análise de Solo da Empresa Baiana de Desenvolvimento Agrícola (EBDA), para análise química dos substratos (Tabela 1). A semeadura foi realizada em bandejas plásticas com diferentes substratos, colocando-se 20 sementes por bandeja, a uma profundidade de 1,0 cm. Em seguida, as bandejas foram levadas para o viveiro de mudas, sendo irrigadas diariamente.

No terceiro dia após a semeadura, iniciou-se o teste de emergência das plântulas, que se estendeu até o $28^{\circ}$ dia, contando-se o número de plântulas emergidas pelo critério de plântulas normais segundo as Regras de Análises de Sementes (RAS) (BRASIL, 1992). Em seguida, foi calculado o índice de velocidade de emergência (IVE), segundo Maguire (1962), utilizando-se a fórmula IVE $=\frac{E_{1}}{N_{1}}+\frac{E_{2}}{N_{2}}+\ldots+\frac{E_{n}}{N_{n}}$, em que $E_{1}, E_{2}, E_{n}$ = número de plântulas normais, computadas na primeira, na segunda e na última contagem; $\mathrm{N}_{1}, \mathrm{~N}_{2}, \mathrm{~N}_{\mathrm{n}}$ = número de dias da semeadura à primeira, segunda e última contagens.

Após as avaliações de germinação (28dia após a semeadura), foram retiradas cinco plântulas de cada tratamento, para avaliar o comprimento da parte aérea
(CA), comprimento da radícula (CR), comprimento da plântula inteira $(\mathrm{CPl})$, comprimento da folha $(\mathrm{CF})$, número de folhas (NF), massa verde da parte aérea (MVA e da radícula (MVR) e massa seca da parte aérea (MSA) e da radícula (MSR). Em seguida, foram pesadas, para determinação da massa verde do sistema radicular (MVR) e da massa verde da parte aérea (MVA). Posteriormente, o material foi acondicionado em sacos de papel e levado à estufa de circulação forçada de ar para secagem a $80^{\circ} \mathrm{C}$, durante 24 h. Após esse período, as amostras foram pesadas novamente, para determinação da massa seca da radícula (MSR) e da parte aérea (MSA).

Os resultados foram analisados estatisticamente e as diferenças entre as médias de cada tratamento, avaliadas pelo teste de Tukey a $\mathrm{p} \leq 0,05$, utilizando-se o programa estatístico ASSISTAT (SILVA; AZEVEDO, 2006).

\section{RESULTADOS}

O comprimento e a largura média das sementes foram de $3,7 \mathrm{~mm}( \pm 0,22) \mathrm{e} 2,7 \mathrm{~mm}( \pm 0,22)$, respectivamente, enquanto o peso de 100 sementes foi de $1,1 \mathrm{~g}$. Esses resultados são semelhantes aos relatados por Feliciano et al. (2008) para a mesma espécie, ou seja, comprimento das sementes entre 2,8 e 3,9 mm e largura entre 2,8 e $3,5 \mathrm{~mm}$.

Pela Tabela 2, verifica-se que o substrato da casca de madeira conduziu às médias superiores quanto ao número de folhas (NF) e comprimento de folhas (CF) em razão, talvez, dos níveis elevados de $\mathrm{Ca}^{++}$e $\mathrm{Mg}^{++}$ (Tabela 1). Quanto ao comprimento das plântulas (CPl), a utilização de solo puro e casca de madeira e da mistura entre bagaço de cana + esterco apresentaram médias semelhantes e superiores às dos demais tratamentos.

O IVE das sementes de aroeira foi menor nos tratamentos com areia e casca de madeira. Os melhores resultados foram observados nos tratamentos com bagaço de cana associado com esterco e, ou, esterco + cinzas, sendo semelhantes também ao tratamento com solo puro e solo + areia e esterco. Esse comportamento sugere que os substratos em referência favoreçam a emergência das plântulas, possivelmente por apresentarem menor impedimento físico à emergência.

Na Tabela 3 são apresentados os resultados das características da parte aérea das plântulas, e a altura

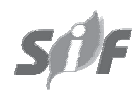

Revista Árvore, Viçosa-MG, v.37, n.4, p.737-745, 2013 
Tabela 1 - Análise química dos substratos utilizados no estudo de emergência e crescimento de mudas de aroeira. Table 1 - Chemical analysis of substrates used in the study of emergence and growth of mastic seedlings.

\begin{tabular}{|c|c|c|c|c|c|c|c|c|c|c|c|c|}
\hline \multirow{2}{*}{ Trat. } & $\mathrm{pH}$ & $\mathrm{C}$ & M. O & $\mathrm{P}$ & $\mathrm{K}$ & $\mathrm{H}+\mathrm{Al}^{3+}$ & $\mathrm{Na}^{+}$ & $\mathrm{Ca}^{2+}$ & $\mathrm{Mg}^{2+}$ & $\mathrm{Ca}^{2+}+\mathrm{Mg}^{2+}$ & SB & CTC \\
\hline & $\left(\mathrm{H}_{2} \mathrm{O}\right)$ & $\mathrm{g} / \mathrm{kg}$ & $\mathrm{g} / \mathrm{kg}$ & $\mathrm{mg} / \mathrm{dm}^{3}$ & $\mathrm{cmolc} / \mathrm{dm}^{3}$ & $\mathrm{mg} / \mathrm{dm}^{3}$ & \multicolumn{6}{|c|}{$\mathrm{mg} / \mathrm{dm}^{3} \mathrm{cmolc} / \mathrm{dm}^{3} \mathrm{cmolc} / \mathrm{dm}^{3}$} \\
\hline T 1 & 6,7 & 1,37 & 2,4 & 74,6 & 0,28 & 0,29 & 0,06 & 6,17 & 1,84 & 8,01 & 8,36 & 8,65 \\
\hline Т 2 & 7,6 & - & - & 6,0 & 0,05 & 0,00 & 0,02 & 0,75 & 0,52 & 1,27 & 1,34 & 1,34 \\
\hline Т 3 & 7,8 & 2,1 & 3,6 & 70,6 & 1,68 & 0,00 & 0,14 & 4,05 & 1,72 & 5,77 & 7,59 & 7,59 \\
\hline T 4 & 6,4 & 4,91 & 8,5 & 99,6 & 1,20 & 1,84 & 0,23 & 11,71 & 3,71 & 15,42 & 16,85 & 18,69 \\
\hline T5 & 9,3 & 4,89 & 8,4 & 237,8 & 6,87 & 0,00 & 0,56 & 4,68 & 3,17 & 7,85 & 15,28 & 15,28 \\
\hline T 6 & 11,6 & 4,9 & 8,5 & 324,0 & 12,12 & 0,00 & 0,87 & 2,96 & 3,3 & 6,26 & 19,25 & 19,25 \\
\hline
\end{tabular}

T1: solo; T2: areia lavada e esterilizada; T3: solo + areia + esterco bovino; T4: casca de madeira; T5: bagaço de cana-de-açúcar + esterco bovino; e T6: bagaço de cana-de-açúcar, esterco bovino e cinzas.

T1: soil; T2: washed and sterilized sand; T3: soil + sand + manure; T4: wood bark; T5: sugar cane bagasse + cattle manure; and T6: sugar cane bagasse + cattle manure + ash.

Tabela 2 - Características morfológicas de germinação e plântulas de aroeira, sob a utilização de diferentes substratos. Table 2 - Morphological characteristics of germination and Mastic seedlings using different substrates.

\begin{tabular}{|c|c|c|c|c|}
\hline Tratamentos & Comp. folhas $(\mathrm{cm})$ & $\mathrm{N}^{\circ}$ de folhas & Comp. plântulas (cm) & IVE (\%) \\
\hline Solo puro & $1,84 \mathrm{~b}$ & $2,00 \mathrm{~b}$ & 6,38 a & $21,39 \mathrm{ab}$ \\
\hline Areia & $1,28 \mathrm{c}$ & $2,00 \mathrm{~b}$ & $3,95 \mathrm{~b}$ & 17,05 bc \\
\hline Solo + Areia + Esterco & 1,55 bc & $2,00 \mathrm{~b}$ & $3,83 \mathrm{~b}$ & $20,28 \mathrm{ab}$ \\
\hline Casca de Madeira & 2,50 a & 2,75 a & 6,60 a & $12,81 \mathrm{c}$ \\
\hline Bagaço de Cana + Esterco & 1,40 bc & $2,00 \mathrm{~b}$ & 6,73 a & 25,05 a \\
\hline Bagaço de Cana + Esterco + Cinzas & 1,40 bc & $2,00 \mathrm{~b}$ & $4,30 \mathrm{~b}$ & 24,90 a \\
\hline C.V $(\%)$ & 12,16 & 9,61 & 11,63 & 13,11 \\
\hline
\end{tabular}

Médias seguidas de mesma letra não diferem de acordo com o teste de Tukey.

Means followed by the same letter do not differ according to Tukey test.

Tabela 3 - Características da parte aérea de plântulas de aroeira, sob a utilização de diferentes substratos.

Table 3 - Characteristics of the Mastic seedlings shoots using different substrates.

\begin{tabular}{lccc}
\hline Tratamentos & Altura parte aérea $(\mathrm{cm})$ & Massa verde $(\mathrm{g})$ & Massa seca $(\mathrm{g})$ \\
\hline Solo puro & $2,85 \mathrm{a}$ & $0,110 \mathrm{~b}$ & $0,030 \mathrm{ab}$ \\
Areia & $1,84 \mathrm{~b}$ & $0,065 \mathrm{c}$ & $0,012 \mathrm{c}$ \\
Solo + Areia + Esterco & $2,03 \mathrm{~b}$ & $0,068 \mathrm{c}$ & $0,018 \mathrm{bc}$ \\
Casca de Madeira & $2,99 \mathrm{a}$ & $0,165 \mathrm{a}$ & $0,038 \mathrm{a}$ \\
Bagaço de Cana + Esterco & $2,16 \mathrm{~b}$ & $0,080 \mathrm{bc}$ & $0,028 \mathrm{ab}$ \\
Bagaço de Cana + Esterco + Cinzas & $2,18 \mathrm{~b}$ & $0,072 \mathrm{c}$ & $0,022 \mathrm{bc}$ \\
C.V $(\%)$ & 12,42 & 16,27 & 26,69 \\
\hline
\end{tabular}

Médias seguidas de mesma letra não diferem de acordo com o teste Tukey.

Means followed by the same letter do not differ according to Tukey test.

da parte aérea (CA) da plântula alcançou melhores resultados com a utilização da casca de madeira e solo puro.

O maior teor de massa verde (MVA) e de massa seca (MSA) da parte aérea foi obtido com o uso de substrato da casca de madeira. Porém, a massa seca das plântulas utilizando substratos de solo puro e a associação entre bagaço de cana + esterco bovino apresentou médias semelhantes ao substrato de casca de madeira.

Os dados da Tabela 4 constituem os resultados das características das raízes das plântulas, não diferindo entre os tratamentos, em nenhuma das variáveis: Comprimento da Radícula (CR), Massa Verde da Radícula (MVR) e Massa Seca da Radícula (MSR).

\section{DISCUSSÕES}

Revista Árvore, Viçosa-MG, v.37, n.4, p.737-745, 2013 
A germinação das sementes teve início no terceiro dia após a semeadura, com porcentagem de 13,75\% $( \pm 1,84)$ de sementes germinadas. Aos 28 dias da semeadura, as porcentagens de emergência foram de 83,8; 65,0; 77,5; 82,5; 87,5; e 91,3\% de germinação, nos tratamentos de solo puro, areia lavada, solo + areia + esterco bovino, casca de madeira, bagaço de canade-açúcar + esterco bovino e bagaço de cana-de-açúcar + esterco bovino + cinzas, em que a utilização de areia lavada e da mistura de areia + solo + esterco bovino resultou em emergência inferior a $80 \%$, percentual este também encontrado por Feliciano et al. (2008).

Os resultados do número e comprimento de folhas tiveram melhores desempenhos (para o substrato casca de madeira), devido aos elevados níveis de $\mathrm{Ca}^{++}$e $\mathrm{Mg}^{++}$ (Tabela 1). O cálcio possui a função de estimular a emissão de novas folhas e o magnésio como o átomo central da molécula da clorofila, garantindo atividade fotossintética inicial, além de bons níveis de quantidade de fósforo e potássio nesse substrato, que pode ter favorecido o maior crescimento desse órgão.

O número de folhas é fator inteiramente ligado ao desenvolvimento da planta, visto que elas são o principal local onde ocorre à fotossíntese. Isso também por serem centros de reserva, fonte de auxina e cofatores de enraizamento, que são translocados para a base, contribuindo, ainda, para a formação de novos tecidos, como as raízes, sendo por isso mais importantes que os caules (PEREIRA et al., 1991; HARTMANN et al., 1997).

Os baixos percentuais do IVE das sementes de aroeira tendo somente areia como substrato pode ter ocorrido pelo baixo percentual de plântulas germinadas. Porém, a utilização de casca de madeira moída apresentou resultados mais baixos em relação aos outros substratos, apesar de ter possibilitado percentual alto de germinação das sementes. Tal fato pode ter sido influenciado pelas características física desse material, que reteve a água, não a disponibilizando para a emergência das plântulas.

De acordo com a análise química dos substratos (Tabela 1), aqueles com maiores quantidades de matéria orgânica apresentaram maior porcentagem de emergência e maior índice de velocidade de emergência, exceto na casca da madeira moída. Esses resultados provavelmente devem estar relacionados a menores taxas de retenção de água e baixa porosidade desses substratos. O baixo percentual de IVE apresentado pelo substrato com casca de madeira pode ter ocorrido por algum efeito alelopático presente nesse composto, dificultando a germinação, ou pela higroscopicidade do substrato, pois a madeira pode ter retido água não a disponibilizado para as sementes.

Segundo Figliola et al. (1993), as interações entre os fatores que influenciam na emergência e germinação de sementes são importantes, visto que a capacidade de retenção de água e a quantidade de luz que o substrato permite chegar à semente podem ser responsáveis por diferentes respostas germinativas. Andrade e Pereira (1994) relataram que a capacidade de retenção de água de cada substrato, aliada às características intrínsecas que regulam o fluxo de água para as sementes, pode influenciar os resultados de germinação de sementes.

Substratos contendo esterco em combinação com os outros componentes, nas proporções usadas, fornecem melhores condições de crescimento (CAVALCANTI; BRITO, 2009).

Souza et al. (2001) verificaram no substrato com maior quantidade de matéria orgânica (terriço de mata + vermiculita) emergência mais rápida para plantas de

Tabela 4 - Características da radicular de plântulas de aroeira, sob a utilização de diferentes substratos. Table 4 - Characteristics of Mastic seedlings roots using different substrates.

\begin{tabular}{|c|c|c|c|}
\hline Tratamentos & Comp. raízes $(\mathrm{cm})$ & Massa verde (g) & Massa seca (g) \\
\hline Solo puro & 2,53 a & 0,0073 а & 0,0025 a \\
\hline Areia & 2,71 a & 0,0113 a & 0,0020 a \\
\hline Solo + Areia + Esterco & 1,93 a & 0,0060 а & 0,0018 а \\
\hline Casca de Madeira & 2,84 a & 0,0118 a & 0,0070 a \\
\hline Bagaço de Cana + Esterco & 2,61 a & 0,0085 a & 0,0035 a \\
\hline Bagaço de Cana + Esterco + Cinzas & 2,11 a & 0,0100 a & 0,0025 a \\
\hline $\mathrm{CV}(\%)$ & 24,49 & 40,28 & 116,10 \\
\hline
\end{tabular}

Médias seguidas de mesma letra não diferem de acordo com o teste de Tukey.

Means followed by the same letter do not differ according to Tukey test. 
cagaita (Eugenia dysenterica), em comparação com os demais substratos. O aumento da germinação em espécies florestais, ao se adicionarem húmus de minhoca como adubação orgânica, foi observado por Berton (1999). A avaliação da germinação de sementes de tamboril (ARAÚJO; SOBRINHO, 2011) resultou em melhores desempenhos de IVE nos substratos de solo + esterco bovino e solo + casca de arroz carbonizada, sendo o resultado atribuído aos maiores valores de matéria orgânica nesses dois substratos. Vieira Neto (1998) observou que substratos compostos por palha de arroz e esterco favoreceram o índice de velocidade de germinação em mudas de mangabeira.

A utilização da casca de madeira e solo puro estimulou o maior crescimento da parte aérea da plântula. Esse resultado pode ter sido influenciado pelos maiores teores de cálcio e magnésio nesses substratos. Provavelmente, esses macronutrientes tiveram fácil disponibilização para o crescimento da parte aérea, em comparação com os substratos contendo maiores teores de matéria orgânica.

Cunha et al. (2006), avaliando o desenvolvimento de mudas de Acácia sp. em diferentes substratos, verificaram na parte aérea das mudas tendência ao maior acúmulo de $\mathrm{P}, \mathrm{K}$ e Mg e maior altura quando cultivadas no substrato com adição de esterco bovino, revelando, nesse substrato, quantidades relevantes desses nutrientes. Gomes et al. (2002), avaliando os parâmetros morfológicos de mudas de Eucaliptus grandis, consideraram a altura da parte aérea atributo muito importante para estimar o padrão de qualidade de mudas, sendo essas características fáceis e viáveis de mensuração, além de não destruírem as mudas.

Oliveira et al. (2011), avaliando o crescimento de Cavanillesia arborea com diferentes substratos, relataram maiores altura da parte aérea das plântulas aos 30 dias utilizando a casca de madeira $+10 \%$ de cinzas, solo $+50 \%$ de areia e solo $+50 \%$ de casca de arroz carbonizada.

Os resultados dos percentuais de MS indicaram que a utilização de areia como substrato apresentou menores percentuais de MS nas plantas quando comparadas com as plântulas germinadas no tratamento com bagaço de cana + esterco $(20,9 \pm 7,90$ e 34,67 \pm 7,54 , respectivamente).
Esses resultados podem ter sido influenciados pelo alto teor de matéria orgânica nesses substratos, principalmente pela adição do esterco bovino. Segundo Correia et al. (2001), o esterco é componente orgânico que melhora as condições físicas do substrato, como aeração e drenagem, além de ser rico em nutrientes, que são rapidamente liberados para as plantas.

O efeito do esterco no incremento da massa verde também foram obtidos por Cavalcanti et al. (2002), avaliando a fitomassa verde de plântulas de imbuzeiro em substrato composto com solo + esterco. Cunha et al. (2005) obtiveram resultados significativos no incremento de massa verde de mudas de ipê- roxo (Tabebuia impetiginosa Mart. ex D.C.) em substratos com esterco. Scalon et al. (2011), avaliando a germinação e crescimento de pau-ferro (Caesalpinia ferrea Mart. ex Tul.) em diferentes substratos, encontraram maiores teores de massa fresca e de massa seca nos tratamentos contendo mistura de solo + areia + adubos orgânicos e solo + areia + adubos químicos, sendo influenciados pelos maiores teores de fósforo nesses substratos.

Coelho et al. (2006), avaliando a influencia de substratos na formação de mudas de guapuruvu (Schizolobium parahyba (Vell.) Blake), encontraram melhores resultados com a utilização de terra vegetal + esterco e areia como substratos. Já Carvalho Filho et al. (2002) obtiveram os melhores resultados da variável peso de matéria seca de folhas, caule e raiz em substratos que continham em sua composição esterco bovino.

Os resultados das características radicular das plântulas foram comprometidos, principalmente, pela profundidade do recipiente (bandejas), servindo como barreira física e inibindo o crescimento, ou, ainda, pelo tempo de duração da avaliação (28 dias).

Scalon et al. (2011), avaliando a germinação e crescimento de pau-ferro (Caesalpinia ferrea Mart. ex Tul.) em diferentes substratos, verificaram que o substrato com terra + areia obteve o maior comprimento médio $(9,8 \mathrm{~cm})$ aos 53 dias após a emergência. Atribuíram a esse fato a baixa disponibilidade de nutrientes e água nesse substrato, forçando as raízes ao maior crescimento axial em busca de nutrientes.

Araújo e Sobrinho (2011) observaram melhores resultados de massa verde nas mudas dos substratos contendo solo + esterco + casca de arroz carbonizada, tendo as médias superiores às das mudas dos substratos 
contendo somente solo, para produção de mudas de tamboril. Cunha et al. (2006) observaram que mudas de Acacia mangium e Acacia auriculiformes apresentaram menor desenvolvimento radicular quando o substrato não continha fonte orgânica. Para Dias et al. (2008), uma possível explicação para esse comportamento seria o fato de o adubo orgânico melhorar a estrutura do solo, permitindo o melhor desenvolvimento do sistema radicular.

Cavalcanti et al. (2002) também observaram que o peso da raiz fresca de umbuzeiro foi maior quando utilizou o tratamento solo + esterco. Clement e Machado (1997) afirmaram que a incorporação de compostos orgânicos nos substratos pode influenciar o desenvolvimento da fitomassa e raízes de determinadas espécies florestais. Carvalho Filho et al. (2002) verificaram, também, que os melhores resultados para peso da raiz seca foi com o substrato que continha esterco bovino.

Observou-se que o peso radicular das mudas de aroeira não foi influenciado pela adição de uma fonte orgânica de nutriente; essa fonte orgânica adicionada ao solo proporciona maior retenção de água, melhora a aeração das raízes e disponibiliza nutrientes para a produção de mudas. Com base nessas informações, pode-se considerar que as mudas de aroeira apresentaram crescimento satisfatório, entretanto o período de avaliação deveria ser maior para o melhor estabelecimento, sobretudo, das raízes.

\section{CONCLUSÕES}

As combinações de substratos conduzem a diferentes respostas na emergência e vigor das sementes.

Os substratos contendo composto de casca de madeira peneirada ou bagaço de cana + esterco fornecem as melhores condições para o crescimento inicial de plântulas de aroeira.

\section{REFERÊNCIAS}

ANDRADE, A. C. S.; PEREIRA, T. S. Efeito do substrato e da temperatura na germinação e no vigor de sementes de cedro - Cedrela odorata L. (MELIACEAE). Revista Brasileira de Sementes, v.16, n.1, p.34-40, 1994.

ANDRIOLO, J. L. Fisiologia das culturas protegidas. Santa Maria: Universidade Federal de Santa Maria, 1999.142p.
ARAÚJO, A. P.; PAIVA SOBRINHO, S. Germinação e produção de mudas de tamboril (Enterolobium Contortisiliquum (vell.) Morong) em diferentes substratos. Revista Árvore, v.35, n.3, suppl. 1, p.581-588, 2011.

BERTON, R. S. Agricultura orgânica.

Campinas: Instituto Agronômico de Campinas, 1999.

BRASIL. Ministério da Agricultura e da Reforma Agrária. Regras para análise de sementes. Brasília: SNDA/DNDV/CLAV, 1992. 365p.

CARVALHO FILHO, J. L. S. et al. Produção de mudas de Cássia grandis L. em diferentes ambientes, recipientes e misturas de substratos. Revista Ceres, v.49, n.284, p.341-352, 2002.

CARVALHO, P. E. R. Espécies florestais brasileiras: recomendações silviculturais, potencialidades e uso da madeira. Colombo: Embrapa-CNPF, 1994. 640p.

CAVALCANTI, N. B. et al. Emergência e crescimento do imbuzeiro (Spondias tuberosa Arr. Cam.) em diferentes substratos. Revista Ceres, v.49, n.282, p.97-108, 2002.

CAVALCANTI, N. B.; BRITO, L.T. L. Efeitos de diferentes substratos no desenvolvimento de aroeira vermelha (Schinus terebibthifolius Raddi). Engenharia Ambiental, v.6, n.3, p.320-332, 2009.

CLEMENT, C. R.; MACHADO, F. M. Efeito da adubação orgânica na produção de biomassa em quebra-pedra (Phyllanthus stipulatus,

Euphorbiaceae) em Manaus, Brasil. Acta

Amazônica, v.27, n.2, p.73-80, 1997.

COELHO, R. R. P. et al. Influência de substratos na formação de mudas de guapuruvu (Schizolobium parahyba (Vell.) Blake). Revista Ciência Agronômica, v.37, n.2, p.149-152, 2006.

CORREIA, D. et al. Alternativas de substratos para a formação de porta enxertos de gravioleira (Annona muricata) em tubetes. Fortaleza: Embrapa Agroindústria Tropical, 2001. (Comunicado Técnico, 67).

Revista Árvore, Viçosa-MG, v.37, n.4, p.737-745, 2013 
CUNHA, A. M. et al. Efeito de diferentes substratos sobre o desenvolvimento de mudas de Acacia sp. Revista Árvore, v.30, n.2, p.207214, 2006.

CUNHA, A. O. et al. Efeitos de substratos e das dimensões dos recipientes na qualidade das mudas de Tabebuia impetiginosa (Mart. Ex D.C.) Standl. Revista Árvore, v.29, n.4, p.507-516, 2005.

DIAS, M. A. et al. Germinação de sementes e desenvolvimento de plantas de pimenta malagueta em função do substrato e da lâmina de água.

Revista Brasileira de Sementes, v.30, n.3, p.115-121, 2008.

FELICIANO, A.L.P. et al. Morfologia de sementes, de plântulas e de plantas jovens de aroeira (Myracrodruon urundeuva Allemão). Revista de Biologia e Ciências da Terra, v.8, n.1, p.110-118, 2008.

FIGLIOLA, M. B.; OLIVEIRA, E. C.; PIÑARODRIGUES, F. C. M. Análise de sementes. In: AGUIAR, I. R.; PIÑARODRIGUES, F. C. M.; FIGLIOLA, M. B. (Coord.). Sementes

florestais tropicais. Brasília: ABRATES, 1993. p.137-174.

GOMES, J. M. et al. Parâmetros morfológicos na avaliação da qualidade de mudas de Eucalyptus grandis. Revista Árvore, v.26, n.4, p.515-523, 2002.

GUERRA, M. E. C. et al. Morfologia de sementes, de plântulas e da germinação de Copaífera langsdorfii Desf (Leguminosae -

Caesalpinoideae). Cerne, v.12, n.4, p.322-328, 2006.

HARTMANN, H. T. et al. Plant propagation: principles and practices. 6.ed. New Jersey: Prentice Hall International, 1997. 770p.

IBAMA. Portaria 006/92-N. Lista oficial das espécies da flora ameaçadas de extinção. Diário Oficial da União, de 15 de jan. de 1992.

LORENZI, H. Árvores brasileiras: manual de identificacão e cultivo de plantas arbóreas nativas do Brasil. Nova Odessa: Plantarum, 1992. 382p.

Revista Árvore, Viçosa-MG, v.37, n.4, p.737-745, 2013
MAGUIRE, J.D. Speed of germination AID in selection and evaluation for seedling emergence and vigor. Crop Science, v.2, n.2, p.176-177, 1962.

MELO, M.G.G.; MENDONÇA, M.S.; MENDES, A.M.S. Análisemorfológica de sementes, germinação e plântulas de jatobá ( Hymenaea intermédia Durkevar. adenotricha ( Ducke) Lee \& Lang.) ( Leguminosae-Caesalpinoideae).

Acta Amazonica, v.34, n.1, p.9-14, 2004.

MORGADO, I.F. et al. Resíduos agroindustriais prensados como substrato para a produção de mudas de cana- de- açúcar. Scientia

Agrícola, v.57, n.4, p.709-712, 2000.

OLIVEIRA, J.S. et al. Avaliação da taxa de germinação e do desenvolvimento de Barriguda (Cavanillesia arborea) com uso de substratos alternativos. Revista de Biologia e Ciências da Terra, v.11, n.1, p.83-88, 2011.

OLIVEIRA, M.N.S. et al. Efeitos alelopáticos de seis espécies arbóreas da família Fabaceae. Unimontes Cientifíca, v.7, n.2, p.121-128., 2005.

OLIVEIRA, R.B. et al. Produção de mudas de essências florestais em diferentes substratos e acompanhamento do desenvolvimento em campo. Ciências e Agrotecnologia, v.32, n.1, p.122-128, 2008.

PEREIRA, F. M. et al. Efeito do ácido indolbutírico no enraizamento de estacas herbáceas de goiabeira (Psidium guajava L.) das cultivares 'Rica' e 'Paluma' em câmara de nebulização. Científica, v.19, n.2, p.199-206, 1991.

SANTIN, D.A.; LEITÃO FILHO, H.F. Restabelecimento e revisão taxonômica do gênero Myracrodruon Freire Allemão (Anacardiaceae). Revista Brasileira de Botânica, v. 14, n.2, p. 133-145, 1991.

SCALON, S.P.Q. et al. Germinação e crescimento de Caesalpinia ferrea mart. Ex tul. em diferentes substratos. Revista Árvore, v.35, n.3, suppl. 1, p.633-639, 2011. 
Estabelecimento inicial de plântulas de Myracrodruon...

SILVA, F. A. S. E.; AZEVEDO, C. A. V. A new version of the Assistat-Statistical Assistance Software. In: WORLD CONGRESS ON COMPUTERS IN AGRICULTURE, 4., 2006, Orlando. Proceedings... Orlando: American Society of Agricultural Engineers, 2006. p.393-396.

SILVA, G.B. et al. Potencial alelopático de espécies arbóreas nativas do Cerrado. Hoehnea, v.33, n.3, p.331-338, 2006.

SODRE,G.A. Substratos e estaquia na produção de mudas de cacaueiro. 2007. 93f. Tese (Doutorado em Produção Vegetal) Faculdade de Ciências Agrárias e Veterinárias UNESP, Campus de Jaboticabal, São Paulo, 2007.
SOUZA, E. R. B. et al. Emergência e crescimento de cagaita (Eugenia dysenterica DC.) em função do tipo e volume de substratos. Pesquisa Agropecuária Tropical, v.31, n.2, p.89-95, 2001.

VIEIRA NETO, R. D. Efeitos de diferentes substratos na formação de mudas de mangabeira (Hancornia speciosa Gomes). Revista Brasileira de Fruticultura, v.20, n.3, p.265-271, 1998.

ZIETEMANN, C.; ROBERTO, S.R. Produção de mudas de goiabeira (Psidium guajava L.) em diferentes substratos. Revista Brasileira de Fruticultura, v.29, n.1, p.137-142, 2007. 
